\title{
Comparative Curriculum Critique and Analysis of Secondary School English Language Teaching
}

\author{
Md. Jahangir Alam ${ }^{1}$ Q (D) $\triangle$ and Tahmina Aktar ${ }^{2}$ Q (D) \\ ${ }^{1}$ Lecturer, Faculty of Languages \& Translation, King Khalid University, Abha, Saudi Arabia \\ 2Lecturer, Community College for Girls, King Khalid University, Abha, Saudi Arabia \\ $\square$ Corresponding Author: Md. Jahangir Alam, E-mail: 2j.alam@gmail.com
}

\begin{tabular}{|c|c|}
\hline ARTICLE INFORMATION & ABSTRACT \\
\hline Received: May 17, 2021 & Good curriculum plays a crucial role in forging life-long learning competencies, social \\
\hline Accepted: June 02, 2021 & attitudes and skills for the learners. Besides it is self-evident that, curriculum plays an \\
\hline Volume: 3 & important role in shaping a nation's future. For obvious reasons, it has been the focal \\
\hline Issue: 6 & point of stakeholders' interests for decades. Formulating an effective curriculum has \\
\hline DOI: 10.32996/ijels.2021.3.6.2 & $\begin{array}{l}\text { been a decade-long pursuit for many nations' education-history. For similar reasons } \\
\text { countries like Bangladesh and Saudi Arabia stand at a historic threshold of decision }\end{array}$ \\
\hline KEYWORDS & making regarding their countries curriculum. Both the countries share some common \\
\hline $\begin{array}{l}\text { ELT, curriculum, comparison, } \\
\text { critique }\end{array}$ & $\begin{array}{l}\text { challenges with respect to their curriculum development and implementation from } \\
\text { the various sectors of society. All these education-challenges and..... all the } \\
\text { experiences that occur within the school or other learning context- what is intended } \\
\text { and what actually becomes a reality in the sphere of curriculum and teaching (Pinar, } \\
\text { 2000) are the subjects of this paper. }\end{array}$ \\
\hline
\end{tabular}

\section{Curriculum Development Process: A Comparative Analysis}

Saudi Arabia and Bangladesh share some similarities and differences in their socio-culture and economic sphere which have characterized their respective ELT curriculum. In Bangladesh, ELT curriculum development is influenced by the long standing language ideology due to the British colonial history and country's language movement in 1971. In contrast, the ELT curriculum in Saudi Arabia is being developed considering English as a foreign language as there is no such postcolonial language legacy. Nevertheless, the main participants of curriculum development of these two countries can be categorized as: Institutional (Education) Political, Socio-cultural and Economic.

\subsection{Institutional Participants}

Since its unification (1932) there were two types of schools in Saudi Arabia: schools for girls and schools for boys. Girls' schooling and curriculum were under the Department of Religious Guidance until 2002, while the education for boys was overseen by the Ministry of Education (Hamdan, 2005). Both the curriculum followed strict religious guidelines. However, in recent years Saudi Arabia has been reforming its economy by a range of initiatives leading to a greater number of citizens participating in private sector investments. One of the important components of the reform initiatives is the role of education development where greater emphasis is put on English language. (Mitchell \& Alfuraih, 2017).

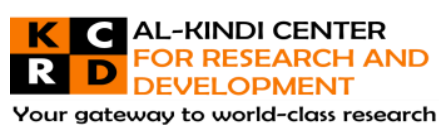

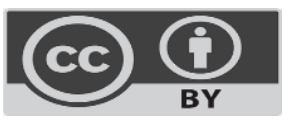

Published by Al-Kindi Center for Research and Development. Copyright (c) the author(s). This open access article is distributed under a Creative Commons Attribution (CC-BY) 4.0 license 


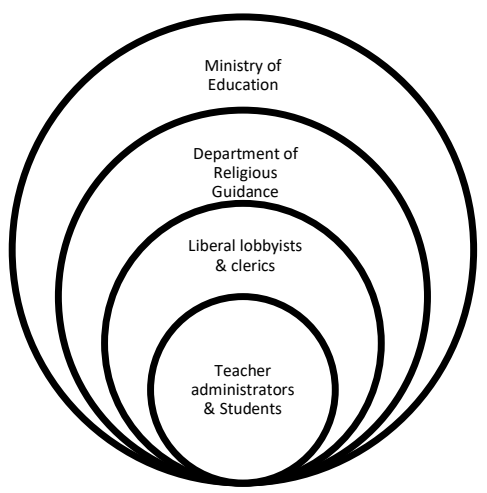

Figure 1: Institutional influences on Saudi Curriculum
Initially in Saudi Arabia, formal education was limited to what was offered in mosques by religious scholars. In the 1920s attempts were taken towards a more state control education (Faruk, 2013). After the unification, King Abdulaziz bin Saud established the Directorate of Education (1925) which later lay the foundations of Ministry of Education.

According to Hamad and Honan (2012) with over 1.7 million students learning English, Bangladesh is one of the largest population in the world learning English. Historically, the debate over whether English is EFL or ESL in Bangladesh has characterized the curriculum development in Bangladesh. Most recently, the Ministry of Education has authorized: English as a second language (National Education Policy, 2010). In Bangladesh, after the independence (1971), National Commission for Education in a report emphasized that English to be taught from 6-12 years (Report on National Commission on education: 1974:14). The National Curriculum and Syllabus Committee (NCSC) formed in 1976 submitted a report, based on that National Curriculum and Textbook Board (NCTB) was formed.

\subsection{Political Participants}

In Saudi Arabia, the first major shift from the Egyptian model (British based) education policy took place in the 1950s and moved towards a more conservative alignment (Al-Nafjan, 2012). During this period of change, in the year 1949 the first higher education college was established in Mecca. For a four-year college degree students were required to take weekly two hours English courses. This also coincides with the establishment of ARAMCO (Arab American Oil company) through which the United States became more economically involved with Saudi Arabia (Faruk, 2013). U.S. involvement in Saudi economy made English language more relevant for social and economic development of Saudi Arabia (Commins, 2008).

In this formation process, the education system continued to be segregated by gender. In the year 1960, the General Administration for Girls' education was established which supervised all levels of female education including female teacher education programs. Reason given behind the separate schools for girls' is 'separate status given to women by Islam' (AlSalloom, 1991:10). From the very beginning, religious values were considered to be the very essence of Saudi curriculum (AlSalloom, 1991).

Whereas, in the British Bengal (then East Bengal) before the partition of the Indian subcontinent in 1947, English was the official language of the British rulers and medium of instructions only to be used in higher education. During its nearly two hundred years of ruling, British governors and viceroys patronized English learning to create a class of faithful administrators for them (Chowdhury \& Kabir, 2014). After partition (which was on the basis of religious identity) in 1947, the then East Pakistan being inspired by the religious ideology realigned the English language policy with Islamic doctrine (Rahman et al., 2010).

Soon after the independence of Bangladesh in 1971, Bangla became the national and "official language" of the country (Rahman, 2010). The first administration under Sheikh Mujib (1971-75) brought about a significant shift in ideological characteristics of education (from Pakistani regime 1947-1971). The inclusion of modern secular beliefs in its constitution underpins the underlying tone of the country's ELT curriculum.

\subsection{Socio-Cultural Participants}

As a social apparatus, the curriculum reflects the educational policies arising out of 'broad district, provincial, national or international priorities' (Nina Bascia et al., 2014:229). The Kingdom of Saudi Arabia is an Islamic state, in which Shari'ah (Islamic law) serves as both constitution and legal framework. On the other hand, Bangladesh, a densely-populated country with an ethnically and linguistically homogeneous population has witnessed the curriculum changes in pursuit of their nationhood and identity. Because of this cultural effect on curriculum both in Saudi Arabia and Bangladesh there arise a kind of teaching, Haberman termed: 'Pedagogy of poverty-not merely what teachers do and what youngsters expect but, for different reasons, what parents, the community, and the general public assume teaching to be' (1990:291). 


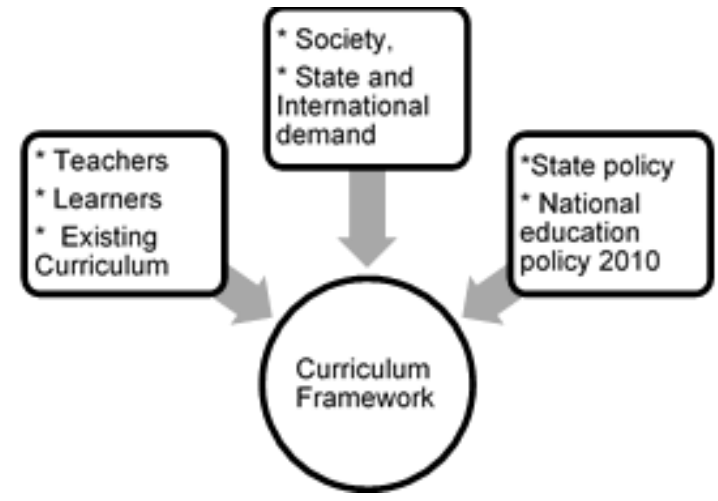

\section{Curriculum Impact on Various Stakeholders}

David Layton suggests, contextually curriculum usually gets developed by balancing 'a range of competing influences' (Layton, 1994, p.13). In process of development, curriculum incurs certain impact on its 'stakeholders'.

\subsection{Impact on Learners}

Learners even though considered to be the prime stakeholders of education-matrix, their voice is little heard in planning a curriculum. This is even more evident in countries like Saudi Arabia and Bangladesh where learners are sometimes perceived to be the objects of the experiment. Reay (2004) observed: schools have evolved considerably over the centuries without having to listen to their students. Sometimes, over emphasis on some particular aspects of the curriculum may lead to undesirable effects on students. For an instance, government decision of over emphasis on national language Bangla is believed to have a negative effect on ethnic minority students based in Chittagong hill tracts whose first language is not Bangla. In Saudi Arabia it is witnessed that, majority of the students graduate from high school without acquiring the basic communicative skills of English language. According to Alghamdi (2014) this problem can be attributed to this culture of ignoring students' voice in curriculum reform. Another aspect of Saudi ELT curriculum is: the differentiation between male and female curriculum which is to have an effect among students. As cultural biases affect teaching which remain hidden in the curriculum and encourage teachersadministrators to think some students might be more capable than others (Zyngier, 2015).

\subsection{Impact on Teachers}

Curriculum modifications often fail to yield expected outcome as policy makers tend to ignore teachers voice (Fullan, 2007). In the case of Saudi Arabia and Bangladesh, teachers' voice is largely under-heard although teachers are at the forefront of the curriculum initiatives. According to the researchers, teachers should not be considered as the passive receptacles of input forwarded by experts of local boards of education (Sarason 1990, Eisner 1992, Tyack and Cuban 1995). According to a study conducted by Noura Alamri (2015): in the EFL context, teachers' voices were marginalized in favor of experts in Saudi hierarchical education system.

One example of lack teachers' participation in Bangladesh is: In 1996, when Communicative Language Teaching (CLT) was introduced in the secondary school curriculum (Rahman, 2015); CLT was never explained properly to the teachers. Therefore, confusion and diverse opinions were circulated among teachers about what will be the effective method of teaching (Das et al., 2104). CLT consequently "stubbornly remains the de facto norm for ELT classrooms" (Rahman \& Pandian, 2018: 46) in Bangladesh without any satisfactory effect.

However, teachers still remain at the center of all improvement endeavors regarding curriculum. Policy makers must ensure teachers' participation in the curriculum development process otherwise, development and implementation will always remain indifferent. As Elliot W. Eisner once sarcastically denounced: 'wisdom flowing from the golden tongues of orators will (never) penetrate the teacher's cortex and transform them from pedagogical mediocrity to an expert' (2000: 347).

\subsection{Impact on Society \& Nationhood}

Curriculum has a deeper implication on society and nationhood in general. Since independence, successive regimes of Bangladesh have been trying to put emphasis on their version of history. Consequently, ELT curriculum in Bangladesh went through multiple changes (from secular to religious and vice-versa) in the last few decades. Various changes are made in the name of constitutional identity to find the proper selves of the Bangladeshi nationhood. Another broad scale implication is to be found in the case of the aboriginal community, as they are losing their cultural identity into the mainstream Bengali culture (an 
example of cultural assimilation). On the other side, in recent decades Saudi curriculum experienced a massive transformation because curricula in their current state were not capable of developing human resources and capability to compete in globalized world. (Mitchell \& Alfuraih, 2017:320). As part of the reform initiatives King Abdullah scholarships were introduced in 2005. Since then, thousands of students went abroad to get higher studies with government support. These measures however are not without criticisms. One opposing argument is, those who are going abroad will adopt Western values (Taleb, 2005) which are against the local customs and traditions.

\section{Curriculum Stated Purposes: Comparative Analysis}

Learners or society in a broad sense is the key and core of the curriculum. Hence, the central purpose of all the curriculum initiatives should be improvement of human competences as realized by Franklin Bobbit about a century ago: 'Human life, however varied, consists in the performance of specific activities. Education that prepares for life is one that prepares definitely and adequately for these specific activities' (1918:42).

\subsection{Stated Purposes: Saudi Curriculum}

The Ministry of Education oversees the Curriculum Department, which formulates and implements the curriculum, creating a unified education system throughout all the districts of Saudi Arabia. In 1970 Ministry of Education released a framework of English language teaching and syllabus at the secondary level. The general objective of the curriculum was "providing students with the opportunity to read science and arts literature in English, developing critical thinking and imaginations" (Mitchell \& Alfuraih, 2017:320).

The Ministry of Education (MoE, General Director of Curriculum, 2002) has stated the general purposes of teaching English in Saudi Arabia as following:

1. To enable students acquire basic language skills (listening, speaking, reading and writing).

2. To develop student's awareness of the importance of English as a means of international communication.

3. To develop student's positive attitudes towards learning English.

4. To enable students acquire the necessary linguistic competence required in various life situations.

5. To enable students acquire the necessary linguistic competence required in different professions.

6. To develop student's awareness about the cultural, economic, religion and social issues of his society and prepare him to participate in their solutions.

7. To develop the linguistic competence that enables student, in future, to present and explain Islamic concept and issues, and to participate in spreading Islam.

8. To enable students linguistically to benefit from English speaking nations, that would enhance the concepts of international cooperation that would develop understanding and respect of cultural differences between nations.

9. To provide students with the linguistic basis that would enable him to participate in transferring other nations' scientific and technological advances that can enhance the progress of his nation.

The underlying values of Saudi curriculum as stated in their curriculum are to build a generation of conscious citizens who can face the challenges on national and international level. And spread the nation's beliefs and culture across the globe.

\subsection{Stated Purposes: Bangladeshi Curriculum}

Curriculum purposes put forward by NCTB (National Curriculum and Textbook Board, Bangladesh) clearly mentions its purpose as an initiative to develop skilled human resources so that to turn the country to a middle income one (NCTB, 2102). It is based on the ideology and vision of the country mentioned in Education Policy 2010. The new curriculum includes contents like work and life oriented education, information and communications technology, climate-change, women development policies etc. Curriculum upholds the values, ideals and inspiration of the Great Liberation War (1971). Among other stated purposes of English curriculum are the following.

1. To acquire competence in all four language skills, i.e. Listening, Speaking, Reading and Writing.

2. To use the competence for effective communication in real life situations at pre intermediate level.

3. To acquire necessary grammar competence in English language.

4. To develop creativity and critical thinking through English language.

5. To become independent learners of English by using reference skills.

6. To use language skills for utilizing information technology.

7. To use literary pieces in English for enjoyment and language learning.

8. To be skilled human resources by using English language skills.

(NCTB Website, p.74)

\section{Curricula: Analysis of Underlying Educational Philosophies and Values}

Curriculum-embedded on cultural norms; has to have some educational philosophies and values which like an undercurrent runs through the education system. Both Saudi Arabia and Bangladesh adopted modern approaches for educating their citizens. Both 
the countries are facing challenges to bridge the gap between expectations (to build a proud independent nation based on their vernacular culture) and reality (for that they have to adopt foreign model of teaching and learning).

\subsection{Educational Philosophies of the Curricula}

Over the recent years, Saudi curriculum was much criticized locally and internationally. To address this obvious crisis, educators have suggested adopting constructivist theories of teaching and learning on a broad scale. Constructivist pedagogy views learning as a process of active development of knowledge. Henceforth, ELT teachers are guided to build their lesson plan based on Communicative Language Teaching (CLT). There are ample references of role play, group work \& pair work in the curriculum. Whereas, apart from Constructivist theory Bangladeshi curriculum focuses on various learning theories like: Trial and Error Theory of Thorndike, the Condition Reflex of Pavlov, Gestalt theory of Koffka and Köhler, the theory of Cognitive Development of Piaget. To realize the knowledge-construct NCTB (2012), Bangladesh underlines the following characteristics of an ideal English language classroom.

1. Learners will create their new ideas and concepts through reflection where they will compare and contrast their previous knowledge, ideas, and experience.

2. Learners themselves will create their own concepts. Teacher will facilitate learners in deciding on work strategies and objectives of their experimentations.

3. Teacher will make scope for learners so that they question their own learning process and reflect on that.

4. Learners will learn from each other in a group through cooperation.

\subsection{Implicit Cultural Norms and Values of the Curricula}

The dominant cultural norm of Saudi curriculum is: upholding religious values and Arab cultural identity. Girls' education and free thinking (against the local customs) which were once taboo in Saudi culture are now becoming common talk among the policy makers. In recent years, Saudi society is increasingly opening up to Western values embracing new ideas. Many students are going abroad with the King Abdullah Scholarship (started in 2006) and incorporating themselves to Western life-style. Whereas, Bangladesh predominantly a Muslim country, trying to find their nationhood based on their native Bengali culture and language. Objectives of the curriculum specify nationalist goals including building awareness among the learners to protect independence, sovereignty and integrity of the country. The NCTB mentions the following features of National Curriculum in 2012.

'Emphasis on patriotism and national integrity on the basis of the Language Movement, the Liberation War, and secularism' (NCTB, Eng.VIII, 2012, p.9).

\section{Curricula: Analysis of Unstated Purposes}

Implicit or hidden social rules make up unstated purposes of the curriculum. From this perspective, the curriculum can be considered as the 'blueprint' of the educational agenda of a nation. Pratt (1994) points out: actual teaching and learning is not curriculum because curriculum refers to instructional acts not the acts of instruction. According to this view curriculum is instructional act stated or unstated.

\subsection{Unstated Purposes of Saudi Curriculum}

Saudi Curriculum has some unwritten social rules or expected behavior which are not taught but assumed to be known. These unstated norms and values can have a wider implication in the classroom. Unstated purposes instilled into the curriculum (consciously or unconsciously) characterize the formation of collective or individual knowledge. Following are some implicit (unstated for that matter) purposes instilled in curriculum.

\subsubsection{Gender Biased}

Implicit or hidden social rules make up unstated purposes of curriculum. In a country run by strict sharia law, girls' education was never an easy task in Saudi Arabia. Society was the main impediment against the initiative taken in favor of girls' inclusion. 'Girls' education was separated from boys in different schools, in the past, they even had to take different subjects and curriculum than the boys' (Alharbi, 2014:2021). 


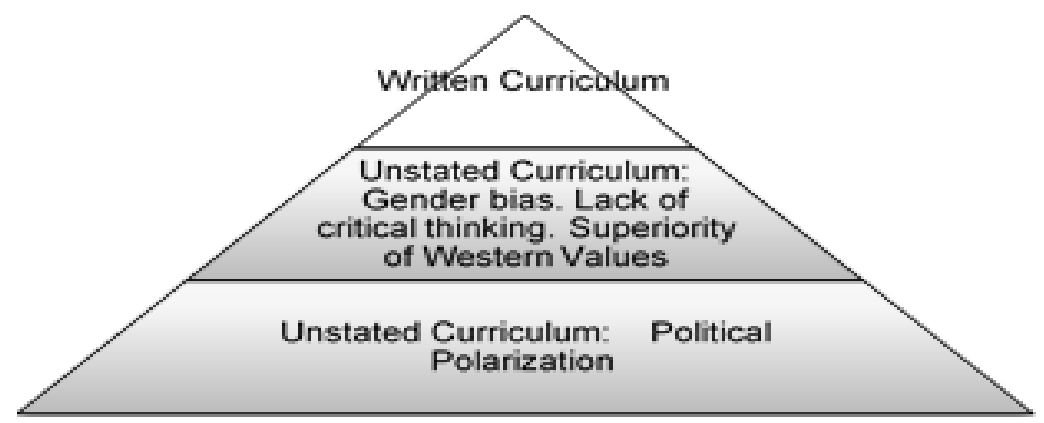

Figure: 3. Unstated Curriculum Iceberg

Girls' education is segregated even today to a large extent. This unstated phenomenon in curriculum creates a society where women's rights are undermined and they are not considered to fit in all the sectors of the society.

\subsubsection{Courses Devoid of Critical Thoughts}

A World Bank study suggests that, Saudi educational system is lacking in "imparting higher-order cognitive skills such as flexibility, problem-solving and judgment" (World Bank, 2002, p. 2). Added to this, the deficiency of critical thinking and analytical approaches to learning and teaching of the curriculum, English or otherwise. (Article published on 'Arab News' 2014). Courses and approaches devoid of critical thinking will eventually generate manpower who will be lacking in critical analytical faculty.

\subsubsection{Dominant Western Values}

Saudi Arabia has adopted western curricula and pedagogy (especially in the field of ELT) with the aim to open up society to the rest of the world. It is for this reason that the curricula, content and pedagogy are often not in tune with the needs of the learners who are rooted in local traditions and identity. This process of westernization may give the impression of superior culture among the students.

\subsubsection{Political Polarization}

Like all the other curricula in the world there are unstated elements of Political polarization in the Saudi curriculum. Saudi schools play a role in introducing the values and norms that support the structure of society and dominant establishment ideals. Teachers convey standards of behavior considered proper by the society and prepare students as agents of established societal structure.

\subsection{Unstated Purposes of Bangladeshi Curriculum}

Bangladesh as a newly independent country (since 1971) has seen ideological changes with the change in power. Each successive government tried to use the curriculum as the mechanism to establish their own agenda. Most of the time they have kept their purposes 'unstated' to avoid criticism.

\subsubsection{Establishing New Political Rhetoric}

Bangladeshi curriculum policies have had particular inclination as the content of education is highly politicized at some points. The two main political parties in Bangladesh have been trying to enact their own version of the country's history of independence (regarding the question of whose contribution was greater in the liberation war). Another example of attaining unstated purposes is the inclusion of portraits of political leaders in the textbook.

\subsubsection{Cultural Assimilation}

Bangladesh although depicted as a monolingual homogenous nation. It faces the issue of suppressing minority language rights, especially from the Chakma tribal community (Rahman, 1999). Bangladeshi curriculum tries to assimilate them into the mainstream culture as they do not have separate curriculum or textbook in their Chakma language.

\section{Influences on the Curricula: Comparative Analysis}

English language today appears to have had the greatest pragmatic success in a variety of Cultural-domains across the globe and is generally considered to be positive (Kachru 1992). It is not only growing in magnitude in the outer circle but in the expanding circle. Native cultures all over the world are in a struggle with the ELT curriculum. 


\subsection{Influences on the Curricula: Cultural Expectations}

While implementing curriculum initiatives Saudis like the rest of the world are constantly being faced with some resistance challenges. Cultural Resistance is a kind of strong defence against the adoption of English as a language of communication.

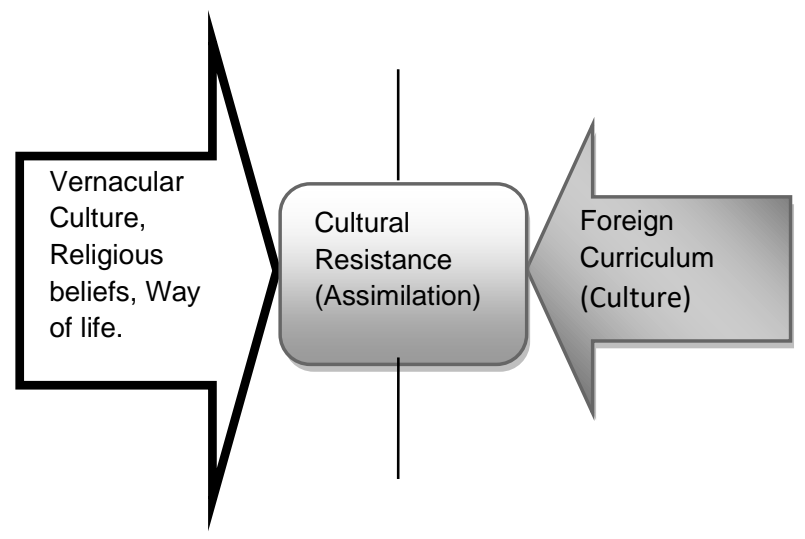

Figure: 4 Cultural Resistance

As a result of cultural resistance, different initiatives are introduced like: Arabic should be used in official meetings, shop title should be in native language, English book translation into Arabic but all of these measures resulted in frustration because of the huge disparity (Arab News, 2014). Finally, the curriculum committee came to term, to introduce books with slight modification (some topics were deleted, some were included). Whereas Bangladesh, because of its British colonial rule which spans for over two centuries, faces little resistance as people are already familiar with English language and culture (which is sometimes negatively attributed to colonial mindset). Nevertheless, Bangladeshi society is strictly hierarchical founded on traditional values. NCTB (2012) tries to address these sensitive issues in the following way: 'Textbooks should reflect social and moral values.... Materials should be sensitive to issues on gender, cultures, color, race, religion, ethnic groups etc.' (NCTB, general Instruction for the writers of textbooks. VI-VIII p.71).

\subsection{Influences on the Curricula: Economic Expectations}

Economic influence on curriculum is heavy and obvious as we see the emergence of different sub-branches of ELT curriculum which are customized and tailored according to the demand of corporate fields. Vested interest of corporations focus on educating their employees for a better return in profits. Henceforth, the emergence of courses like: ESP (English for specific purposes). Government financing education with the expectation that educated students will contribute to the economy. In 1995 the secondary curriculum in Bangladesh underwent a massive change, with the influence of a free market economy. In the secondary curriculum documents, there is an objective to prepare the youths to be competitive in the global marketplace. Failure to generate employment was identified as the major curriculum concern, and eventually practical knowledge became dominant over theoretical knowledge. The government wants to equip citizens to be competitive nationally and internationally. Following agenda drawn from the curriculum of NCTB demonstrate how the government policies upheld the open market economy:

'Emphasis on developing science-minded, rational, work-oriented, skilled human resources...creating human resources compatible for local contexts.... developing human resources in line with the demand of globalization' (NCTB, 2012, p. 10)

To implement the NCTB curriculum guidelines Education board introduced 'Business Studies' as a discipline at secondary level. The intention is to give students the necessary skills and attitudes that they can become self-employed or be useful in the field of economy. With the advent of economic momentum gained by the huge oil revenue in the 1960s, Saudi Arabia realized the importance of ELT to be incorporated in the curriculum. 'It was the close relationship between KSA and US which made English and ELT more relevant to Saudi economic and social development' (Faruk, 2013:75).

\subsection{Influences on the Curricula: Vested Interest of Party Politics}

The choice and deployment of curriculum components, and the interpretation and use of their results, are subject to a range of educational, public and political influences (Black \& Wiliam, 2005). Some state policies directly influence the intended curriculum and resources to enact the curriculum. Bangladesh, a densely-populated country with an unusual ethnically and linguistically homogeneous population, has seen political competition over the definition of national identity as successive regimes have been trying to stamp their own brand of nationhood on a growing population (Naoimi Hossain et al, 2002). In a newly liberated 
country (1971) the first administration under Sheikh Mujib (1971-75) brought some critical ideological changes of education policies (from Pakistani regime 1947-1971). The inclusion of secular values and socialistic society in the curriculum was two priorities. Ziaur Rahman regime (1975-1981) marked a break with socialism and secularism and took a rightward shift in policy orientation. After a decade of shifts and changes, the articulation of political and nationalistic goals in education policy can be seen in the first official National Education Policy document which was produced by the Awami League Administration (19962000) (Alam et al., 2001). The objectives specify the nationalist goals including awareness in the learners to protect the independence, sovereignty and integrity of Bangladesh.

\section{Curricula: Implications for Future Practices}

'How a society selects, classifies, distributes, transmits and evaluates the educational knowledge it considers to be public, reflects both the distribution of power and principles of social control' Bernstein (1971:47). In today's world, curriculum plays a pivotal role in improving society and economy. It also can provide solutions to the pressing conditions like: poverty, social harmony, climate change etc. In addition to this, new challenges have emerged with the advent of globalization such as: Information and Communication Technologies (ICTs); Learning to Live Together (LTLT); Sustainable Development; intercultural understanding; Life skills etc. Curriculum is increasingly called upon to instill these skills among students. However, is the curriculum answer to the future challenges? Answer to this question lies within the contextual characteristics of a curriculum. However, curriculum hidden or written, explicit or implicit will always have deeper consequences.

\subsection{Future Curriculum Implications of Digital Age}

In both the contexts (Saudi Arabia \& Bangladesh) learning through digital media (social and mobile media, e-learning) has become an important phenomenon. The emergence of information and instructional technologies and their implications on teaching and learning has brought about significant changes in the education field in Saudi Arabia. The anytime-anywhere approach to teaching and learning has gained popularity rapidly. This new learning trend has made it compulsory for teachers to equip themselves with their technical-expertise. So, it is apparent that future education will get molded with the present-day curriculum and digital technology each affecting the other. Bangladesh, a middle income developing country has been experiencing digital media effects. Country's Curriculum Board clearly mentions: 'The Vision 2021 in Bangladesh aims at working for a digital Bangladesh and upgrading Bangladesh as a country of middle income.' (NCTB, 2012:2).

\subsection{Future Implications of Societal Curriculum}

Societal curriculum constitutes a major component in shaping knowledge and understanding. Societal curriculum (Cortes, 1981) is the informal curriculum of family and friends' neighborhood mass media. In Bangladesh and Saudi Arabia, society is changing at a rapid speed. The Arab world's media landscapes experienced fundamental shifts since the mid-1990s due to the development of satellite TV, mobile telephony, and the Internet (Kraidy 2002; Rinnawi 2011). Social media like: Facebook, YouTube are playing a critical role in building perceptions and they will play an even greater role in future. It will be challenging for the curriculum developer of both the countries to incorporate these features in the future curriculum.

\subsection{Who Benefits Who Loses}

Curriculum is centered on the interest of its stakeholders. They are the individuals or institutions that are interested in the school curriculum. Learners although the nucleus of all education endeavors, their voice is subdued in most of the cases. This is even more evident in the developing countries like Bangladesh. Learners are considered as entities of experiment and curriculum is being developed over the years through trial and error. In the academic institutions, teachers along with the school administrators have a great stake or concern about the content and structure of curriculum. Politicians as the state agents use curriculum as a mechanism to implement their agenda. The repeated change of secondary school curriculum in Bangladesh is just one example of party interest exerted through curriculum. Students, aboriginal \& tribal communities, minority groups in society (whose voice is less heard), women are on the losing side of the curriculum paradigm.

\subsection{Relative Advantages \& Disadvantages}

There are some obvious advantages of having an effective curriculum especially when the task is teaching and learning English. Curriculum has the potential to make the lesson highly structured and efficient. In countries like Saudi Arabia and Bangladesh where education is still at its probationary stage, curriculum works as a safeguard for ensuring some level of task achievements. In the case of Saudi Arabia, the future appears bright because local educators are sharing ideas with education leaders from across the globe: This means that native educators can benefit from them in order to improve its school system. (Alharbi, 2014).

In case of Bangladesh because of being highly structured, curriculum may not fit in all the contexts especially to the tribal hill track areas. According to White (1988) no curriculum of the world is value-neutral, which is to say, that does not collide with the local social values. Bangladeshi society like the Saudis is strictly characterized by hierarchical terms established by tradition. 
Because of this, teachers are usually authoritative and authoritarian in the classroom. This situation does not akin to the modern curriculum standard values.

\section{Conclusion}

The education system and curriculum are like mirrors that reflect a country or nation's values and expectations. Each country has their own culture and values that is why curricula are varied across culture. Both Saudi and Bangladeshi curricula are being criticized due to the considerable gap between the expectation and reality. The very nature and structure of the curriculum is so intriguing that it requires unified effort and fruitful research to prepare an effective curriculum. Teachers and academicians together with other stakeholders should work to formulate a curriculum which will enable all students to learn by being focused on thinking and reasoning and grounded in mastery of complex bodies of knowledge. (Resnick, 2010).

\section{References}

[1] Alghamdi, D.J., (2014). Student Voice: Its impact on school reform efforts and the reasons behind the success Saudis accomplished in learning English language in Canada comparing to their unsuccessful experiences in Saudi Arabia. International Journal of Arts and Sciences, 07 (3): $323-335$. (OISE) Toronto, Canada

[2] Alharbi, F. (2014). The Development of Curriculum for Girls in Saudi Arabia. Creative Education, (5). 2021-2026. University of Kansas, Lawrence, USA.

[3] Alamri, N. (2015). Teacher voice in curriculum development in Saudi Schools. International Institute of Social and Economic Sciences (IISES). Rome. DOI: $10.20472 / I A C .2015 .015 .014$

[4] Al-Nafjan, E. (2012, April 23). Teaching Intolerance. Foreign Policy. Retrieved from: http://www.foreignpolicy.com/articles/2012/04/23/teaching intolerance

[5] Al-Salloom, H. I. (1991). History of educational movement in the Kingdom of Saudi Arabia. Washington: International Grafeix. [6] Arab News, (Article: Winds of change: English teaching in Saudi Arabia by Ozma Siddique) Retrieved from http://www.arabnews.com/news/567896 Published — Friday 9 May 2014.

[7] Bernstein, B. (1971). On the classification and framing of educational knowledge, in: M. F. D. Young (Ed.) Knowledge and control (London, CollierMacmillan), 47-69

[8] Bobbitt, F. (1918). The Curriculum, Boston: Houghton Mifflin

[9] Commins, D. D. (2008). The Wahhabi Mission and Saudi Arabia. London: I.B.Tauris \& Co. Ltd.

[10] Chowdhury, R. \& Kabir, A. H. 2014. 'Language wars: English education policy and practice in Bangladesh.' Multilingual Education, 4(1), 1-16. [11] Das, S., Shaheen, R., Shrestha, P., Rahman, A. \& Khan, R. 2014. 'Policy versus ground reality: Secondary English language assessment system in Bangladesh.' Curriculum Journal, 25(3), 326-343.

[12] Eisner, E.W., (2000). Those who ignore the past...12 'easy' lessons for the next millennium, Journal of Curriculum Studies, 32:2, 343-357, DOI: $\underline{10.1080 / 002202700182808}$

[13] Eisner, E. W., (1992). Educational reform and the ecology of schooling. Teachers College Record, 93(4), 610-627.

[14] Elyas, T. (2008). The Attitude and Impact of the American English as a Global Language Within The Saudi Education System. Novitas-Royal, Vol: 2 (1), 28-48. ISSN: 1307-4733, University of Adelaide, Australia

[15] Elyas, T., \& Picard, M. (2013). Critiquing of Higher Education Policy in Saudi Arabia: Towards a New Neoliberalism. Education, Business and Society: Contemporary Middle Eastern Issues, 6, 31-41.

[16] Faruk, S.M.G. (2013). English Language Teaching in Saudi Arabia: A world System Perspective. Transaction on Modern Languages. Vol-12, No. 1-2, Scientific Bulletin of the Politechnica University of Timișoara, Romania.

[17] Fullan, M. 2007. The New Meaning of Educational Change, 4th edn. London \& New York: Routledge.

[18] Haberman, M. (1991). The Pedagogy of Poverty Versus Good Teaching. The Phi Delta Kappan, The Phi Delta Kappan, International, Vol.73, No.4, 290-294.

[19] Hamdan, A. (2005). Women and Education in Saudi Arabia: Challenges and Achievements. International Education Journal, 6, $42-64$.

[20] Hamid, M. O. \& Honan, E. 2012. 'Communicative English in the primary classroom: Implications for English-in-education policy and practice in Bangladesh.' Language, Culture and Curriculum, 25(2), 139-156.

[21] Hossain, N. \& Subramanian, R. \& Kabeer, N. (2002). The politics of education expansion in Bangladesh, Ids Working Paper, 167, Institute of development studies, Brighton, UK.

[22] Kachru, B. B. 1992. Models for non-native Englishes. In Kachru (ed.) The Other Tongue: English Across Cultures. Oxford: Pergamon: 31-57

[23] Kraidy, M. 2002. "Arab Satellite Television Between Regionalization and Globalization." Global Media Journal 1 (1).

[24] Ministry of Education (2002). General Directorate of Curricula (2002) English for Saudi Arabia. Jeddah, Saudi Arabia: Almadina Almunawara Press.

[25] Ministry of Education. (2015). Directorates of education in the Kingdom. Retrieved from https://www.mohe.gov.sa/en/default.aspx 
[26] Mitchell, B., \& Alfuraih, A. (2017). English language teaching in the Kingdom of Saudi Arabia: Past, present and beyond. Mediterranean Journal of Social Sciences, 8(2), 317-317.

[27] NCTB (National Curriculum \& Textbook Board Bangladesh) Retrieved from http://www.nctb.gov.bd/cmp/curriculum/English1440352774.pdf[28] National Education Policy 2010. Ministry of Education. 2010. Dhaka: Ministry of Education.

[29] Nina Bascia et al.. (2014). Teachers, curriculum Innovation, and Policy Formation, Curriculum Inquiry, 44:2, P.229,

DOI: $10.1111 /$ curi.12044

[30] Layton, D. 1994. A school subject in the making? The search for fundamentals. In Layton, D. (Ed.) Innovations in science and technology education. Vol. V. Paris: UNESCO, 11-28.

[31] Pinar, W.F. (2000). Curriculum studies: The reconceptualization. Troy, NY: Educator's International Press.

[32] Pratt, D. (1994). Curriculum planning: A handbook for professionals. Fort Worth: Harcourt Brace College Publishers.

[34] Rahman, A. (1999). English Language Teacher Education in Bangladesh: Towards an Alternative Paradigm. Phd. Thesis. University of London. UK. [35] Rahman, M. M., Hamzah, M. I. M., Meerah, T. S. M. \& Rahman, M. 2010. 'Historical development of secondary education in Bangladesh: Colonial period to 21st century.' International Education Studies, 3(1), 114-125.

[36] Rahman, M. M., \& Pandian, A. (2018). A critical investigation of English language teaching in Bangladesh: Unfulfilled expectations after two decades of communicative language teaching. English Today, 34(3), 43-49.

[37] Reay et al., (2004). Consultation in the classroom: Developing dialogue about teaching and learning. Cambridge, UK: Pearson.

[38] Report of the National Commission on Education, 1974. Ministry of Education, Government of Bangladesh.

[39] Resnick, L. (2010). Nested learning systems for the thinking curriculum, Educational Researcher, Vol. 39

[40] Rinnawi, K. 2011. "Arab Internet: Schizophrenic Trilogy." In Arab Media: Globalization and Emerging Media Industries, edited by N.

[41] Sarason, S. B. (1990). The Predictable Failure of Educational Reform: Can We Change Course Before It's Too Late? (San Francisco, CA: Josset-Bass) [42] Taleb, S. A. (2005, September 6). Changing the national curriculum of Saudi Arabia. Islam Daily. Retrieved from

http://www.islamdaily.org/en/saudi-arabia/3438.changing-the-national-curriculum-of-saudi-arabia.htm

[43] Tyack, D. and Cuban, L. (1995). Tinkering Towards Utopia: A Century of Public School Reform, (Cambridge, M.A.: Harvard University Press)

[44] White, R. V. 1988. The ELT Curriculum. Oxford: Blackwell.

[45] Zyngier, D. (2015). Culture and Pedagogy (ies): (What) Have We Learned From and Since Alexander 2001. The Sage Handbook of Curriculum, Pedagogy and Assessment, II. P.172 